\title{
Postpartum Deterioration of Hemodynamics in a Case of Uncorrected Ebstein's Anomaly
}

\author{
Masato Kimura, ${ }^{1}$ Shuhei Kakizaki, ${ }^{1}$ Seiichi Tazawa, ${ }^{1,2}$ Osamu Adachi, ${ }^{3}$ \\ Yoshikatsu Saiki, ${ }^{3}$ and Shigeo Kure ${ }^{1}$ \\ ${ }^{1}$ Department of Pediatrics, Tohoku University Graduate School of Medicine, Miyagi, Sendai 980-8574, Japan \\ ${ }^{2}$ Department of Pediatric Cardiology, Nagano Children's Hospital, Toyoshina, Nagano 399-8288, Japan \\ ${ }^{3}$ Division of Cardiovascular Surgery, Tohoku University Graduate School of Medicine, Miyagi, Sendai 980-8574, Japan
}

Correspondence should be addressed to Masato Kimura, mkimura774@med.tohoku.ac.jp

Received 10 May 2012; Accepted 6 June 2012

Academic Editors: M.-H. Jim and K. Roberts-Thomson

Copyright (c) 2012 Masato Kimura et al. This is an open access article distributed under the Creative Commons Attribution License, which permits unrestricted use, distribution, and reproduction in any medium, provided the original work is properly cited.

\begin{abstract}
Ebstein's anomaly is a rare congenital cardiac malformation that is characterized by abnormalities of the tricuspid valve and right ventricle. Pregnancy is usually well tolerated unless cyanosis or arrhythmia develops. We report a case with Ebstein's anomaly, whose condition was asymptomatic before pregnancy but remarkably deteriorated down during the postpartum period, even though a successful pregnancy and cardiac surgery were achieved. Women with Ebstein's anomaly should be carefully assessed and may need to be advised to have corrective surgery prior to pregnancy even if they were asymptomatic.
\end{abstract}

\section{Introduction}

Ebstein's anomaly is a rare congenital cardiac anomaly [1]. The malformation consists of apical displacement of the tricuspid valve (plastering of the leaflets to the endocardium) with dilatation of the atrialized portion of the right ventricle. The common cardiac anomalies associated with the condition are atrial septal defect and accessory pathway (e.g., Wolff-Parkinson-White syndrome). The clinical spectrum is varied; patients may be asymptomatic throughout their lives or may need to undergo surgery in the neonatal period. In Ebstein's anomaly, pregnancy is usually well tolerated unless cyanosis or arrhythmia develops, yet there is an increased risk of prematurity and low birth weight [2]. We report here a patient with Ebstein's anomaly, whose condition was asymptomatic before pregnancy but remarkably deteriorated down to the level of NYHA functional class IV during the postpartum period, even though a successful pregnancy and cardiac surgery were achieved. It should be recognized that the postpartum period is also a risk stage for women with Ebstein's anomaly.

\section{Case Report}

A 28-year-old primigravida was referred to our hospital at 13 weeks of pregnancy. She had been diagnosed with Ebstein's anomaly and an associated atrial septal defect at 3 years of age. She had been asymptomatic without medication. At age 25 , she underwent cardiac catheterization for hemodynamic assessment anticipating a subsequent pregnancy. It revealed that her left arterial oxygen saturation $\left(\mathrm{SaO}_{2}\right)$ was $93 \%$, with good left ventricular function (Table 1). Surgical intervention was recommended due to severe tricuspid regurgitation and a remarkably enlarged, atrialized right ventricle. She declined to undergo surgery and became pregnant at the age of 28. At the first medical examination conducted at our hospital, she had no respiratory failure and had good percutaneous oxygen saturation $\left(\mathrm{SpO}_{2}\right)$ of $93 \%$. A chest $\mathrm{X}$-ray confirmed cardiomegaly with a cardiothoracic ratio (CTR) of 54\% (Figure 1(a)), and echocardiography revealed a dilated right atrium, a septal leaflet displaced by $50 \mathrm{~mm}$ from the tricuspid annulus, moderate tricuspid regurgitation (Carpentier's type C), and an ostium secundum atrial septal 


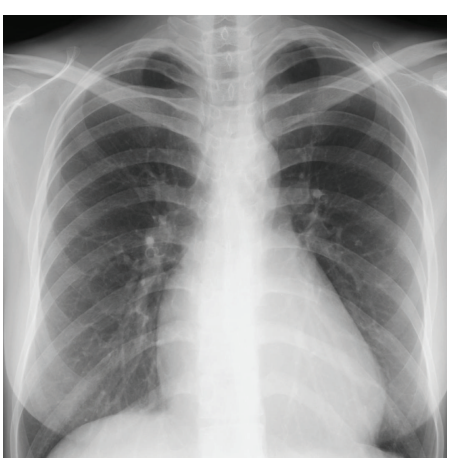

(a)

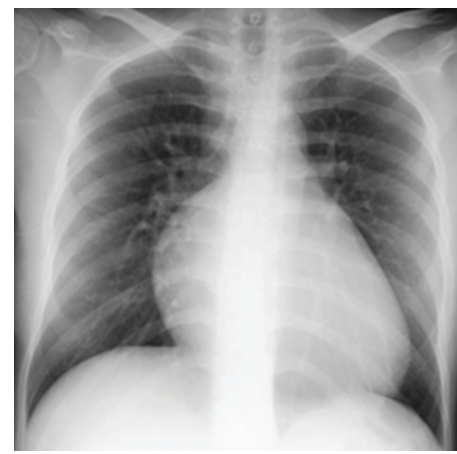

(d)

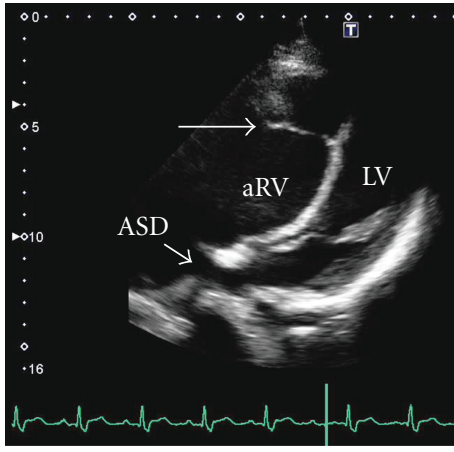

(b)

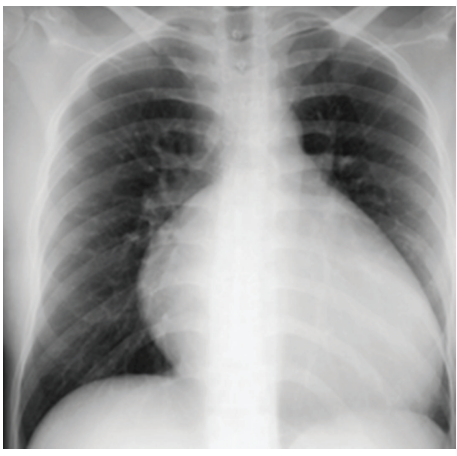

(e)

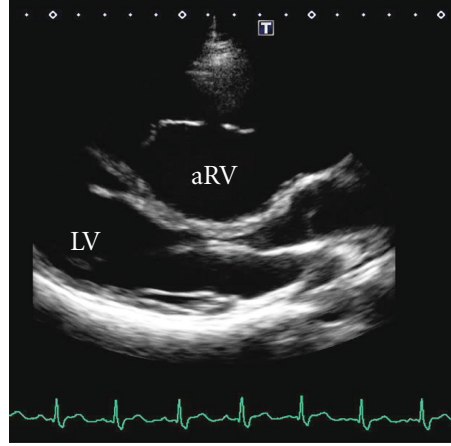

(c)

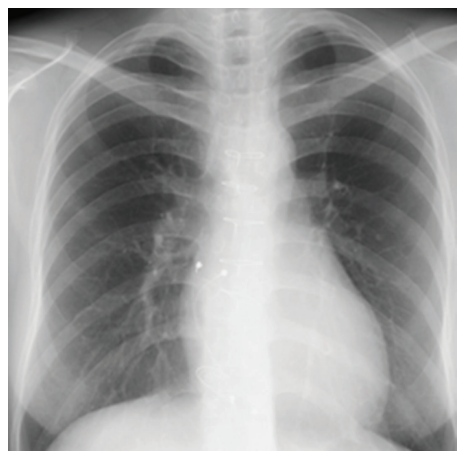

(f)

Figure 1: Chest X-rays (a, d-f) and echocardiographic images (b, c). Chest X-rays taken at gestational age (GA) 13 weeks (a), GA 33 weeks (d), 2 months postpartum (e), and three months after surgery (f). Cardiothoracic ratios were 54\%, 63\%, 70\%, and 48\%, respectively. Echocardiography performed at GA 13 weeks demonstrated apical displacement of the tricuspid valve (arrow) and an atrial septal defect (arrowhead) (b). Displacement of the interventricular septum by the atrialized portion of the right ventricle was observed both in systole (b) and diastole (c). aRV: atrialized right ventricle.

defect (Figure 1(b)). Left ventricular systolic function was preserved, though the interventricular septum was displaced by the enlarged, atrialized right ventricle (Figure $1(\mathrm{c})$ ). At 22 weeks' gestation, her $\mathrm{SpO}_{2}$ decreased to $89 \%$, and oxygen was administered by nasal cannula for cyanosis along with anticoagulation therapy (heparin) to prevent occult embolism. She was admitted at 27 weeks' gestation with dyspnea on exertion. Echocardiography revealed worsening tricuspid regurgitation and right side volume overload, but left ventricular systolic function seemed to be maintained. Although fetal growth was appropriate, elective cesarean section was performed at 33 weeks' gestation due to her respiratory failure and progressive desaturation with worsening cardiomegaly (Figure 1(d)). Her baby, weighing $1943 \mathrm{~g}$ (appropriate for date), was delivered with respiratory distress syndrome and required surfactant treatment. Pathological examination of the placenta was appropriate for gestational age. Two months after delivery, the mother's cardiac condition worsened to the level of NYHA class IV. A chest radiograph confirmed progressive cardiomegaly with a CTR of $70 \%$ and decreased pulmonary blood flow (Figure 1(e)). Urgent cardiac catheterization revealed $\mathrm{SaO}_{2}$ was $77 \%$ even with $\mathrm{O}_{2}$ administration, and a right-to-left shunt of 39\%. Left ventricular function was severely impaired (Table 1). She underwent surgical repair with tricuspid valve replacement using a bioprosthetic valve (Epic Stented Tissue Valve, St. Jude Medical Inc, St Paul, MN) and ASD closure. A pacemaker was implanted (Reply DR, Sorin, Saluggia, Italy) due to complete AV block. During the postoperative period, diuretics (furosemide and aldactone), an angiotensin converting enzyme inhibitor (imidapril) and a beta-blocker (bisoprolol) were initiated. She was discharged in good hemodynamic condition with an ejection fraction of 57\%, and she has remained well with an improved of CTR of $48 \%$ (Figure 1(f)).

\section{Discussion}

Presence of Ebstein's anomaly in a pregnant woman is not an indication for termination of pregnancy or a sufficient finding to advise against becoming pregnant [2]. In our patient, however, her heart condition deteriorated from NYHA class I before pregnancy to NYHA class IV in the postpartum period. It was difficult prior to pregnancy to predict such a striking hemodynamic change, and her hemodynamic condition deteriorated dramatically after delivery (Table 1). In general, plasma volume increases by as much as $50 \%$ in the third trimester [3], and we believe this is what induced dilation of the right atrium and atrialized right ventricle, 
TABLE 1: Hemodynamic data on cardiac catheterization.

\begin{tabular}{|c|c|c|c|c|c|c|c|c|c|}
\hline & $\begin{array}{c}\text { aAo } \mathrm{SpO}_{2} \\
(\%)\end{array}$ & Qp/Qs & $\begin{array}{c}\text { L-R shunt } \\
(\%)\end{array}$ & $\begin{array}{c}\text { R-L shunt } \\
(\%)\end{array}$ & $\begin{array}{c}\text { mPAp } \\
(\mathrm{mmHg})\end{array}$ & $\begin{array}{c}\mathrm{RA} \\
(\mathrm{mmHg})\end{array}$ & $\begin{array}{c}\text { LV/edp } \\
(\mathrm{mmHg})\end{array}$ & $\begin{array}{c}\text { LVEF } \\
(\%)\end{array}$ & TR \\
\hline $\begin{array}{l}\text { Antepartum } \\
\text { (25 years old) }\end{array}$ & 92.7 & 1.6 & 47 & 15 & 13 & 8 & $110 / 7$ & 60.0 & severe \\
\hline Postpartum & 76.8 & 1.2 & 49 & 39 & 21 & 17 & $105 / 18$ & 12.6 & severe \\
\hline (29 years old) & $\left(\mathrm{O}_{2} 2 \mathrm{~L}\right)$ & & & & & & & & \\
\hline
\end{tabular}

aAo: ascending aorta, $\mathrm{SpO}_{2}$ : percutaneous oxygen saturation; Qp/Qs: pulmonary/systemic blood flow ratio; mPAp: mean pulmonary artery pressure; RA: right atrium, edp: end-diastolic pressure; LV EF: left ventricular ejection fraction; TR: tricuspid regurgitation.

resulting in an increased right-to-left shunt volume. The dilated right ventricle aggravated tricuspid regurgitation, which led to reduced pulmonary blood flow in the presence of a right-to-left shunt. Furthermore, left ventricular (LV) function was severely impaired in the postpartum period (Table 1). In a subgroup of patients with Ebstein's anomaly, LV dysfunction is innate [4]; however, this was not the case in our patient. On echocardiography, the ratio of transmitral Doppler early filling velocity to tissue Doppler early diastolic mitral annular velocity $\left(\mathrm{E} / \mathrm{e}^{\prime}\right)$ worsened from 4.8 at 20 weeks' pregnancy to 8.8 at two months after delivery. We suspect that the dilated, atrialized right ventricle interfered with LV diastolic function and that the superimposed severe cyanosis impaired both systolic and diastolic LV function. Moreover, two hemodynamic changes occur after normal delivery: the so-called autotransfusion of blood from the contracting uterus, which increases preload, and an increase in total vascular resistance, which increases afterload. Furthermore, as a physiological adaptation, augmented myocardial contractility declines after delivery [3]. These factors might have exacerbated heart failure in our case.

This case report suggests that women with Ebstein's anomaly should be carefully assessed and may need to be advised to have corrective surgery prior to pregnancy. Since significant hemodynamic changes occur after delivery, a patient with an uncorrected Ebstein's anomaly may be particularly susceptible to heart failure in the postpartum period.

\section{References}

[1] R. M. Freedom and S.-J. Yoo, "Ebstein's malformation of the tricuspid value," in The Natural and Modified History of Congenital Heart Disease, R. M. Freedom, S. Yoo -J, and H. Mikailian, Eds., pp. 91-96, Wiley-Blackwell, New York, NY, USA, 1st edition, 2004.

[2] J. E. Donnelly, J. M. Brown, and D. J. Radford, "Pregnancy outcome and Ebstein's anomaly," British Heart Journal, vol. 66, no. 5, pp. 368-371, 1991.

[3] C. K. Silversides and J. M. Colman, "Physiological changes in pregnancy," in Heart Disease in Pregnancy, C. Oakley and C. A. Warens, Eds., pp. 6-17, BMJ Books, Blackwell Publishing, Oxford, UK, 2nd edition, 2007.

[4] C. H. Attenhofer Jost, H. M. Connolly, P. W. O’Leary, C. A. Warnes, A. J. Tajik, and J. B. Seward, "Left heart lesions in patients with ebstein anomaly," Mayo Clinic Proceedings, vol. 80, no. 3, pp. 361-368, 2005. 


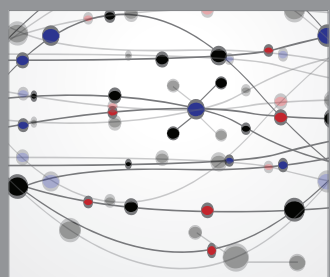

The Scientific World Journal
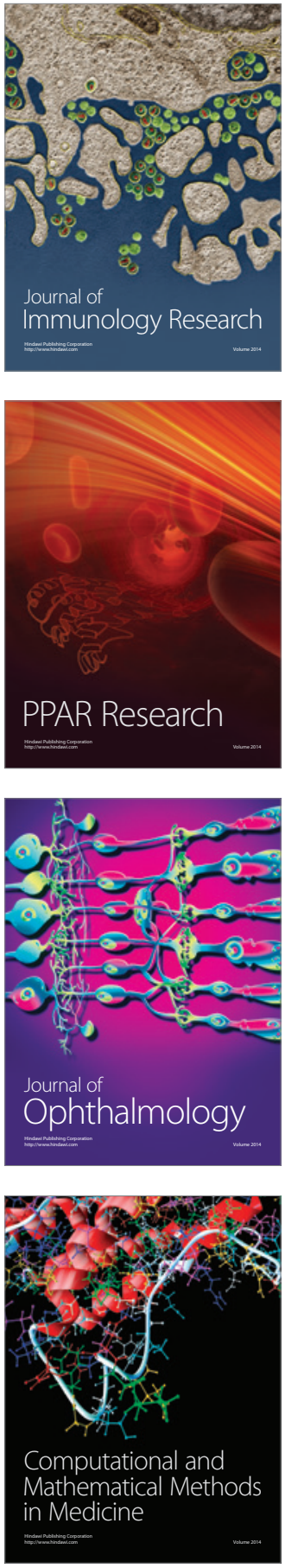

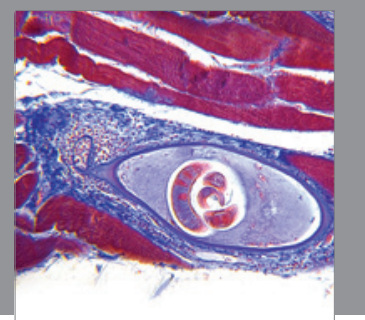

Gastroenterology

Research and Practice
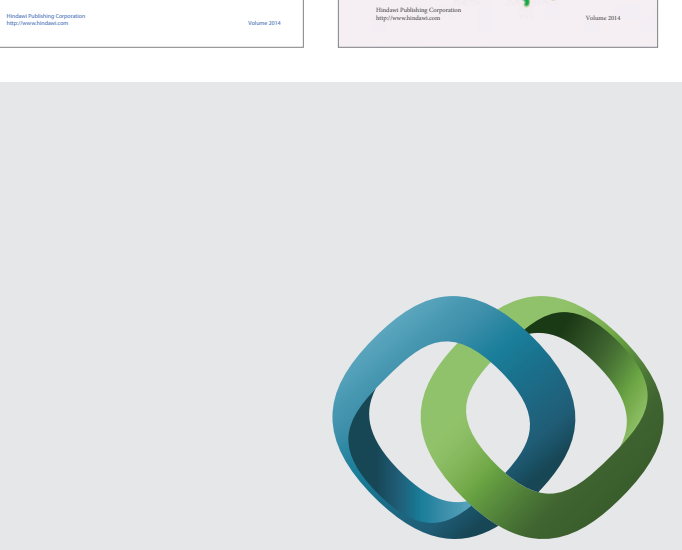

\section{Hindawi}

Submit your manuscripts at

http://www.hindawi.com
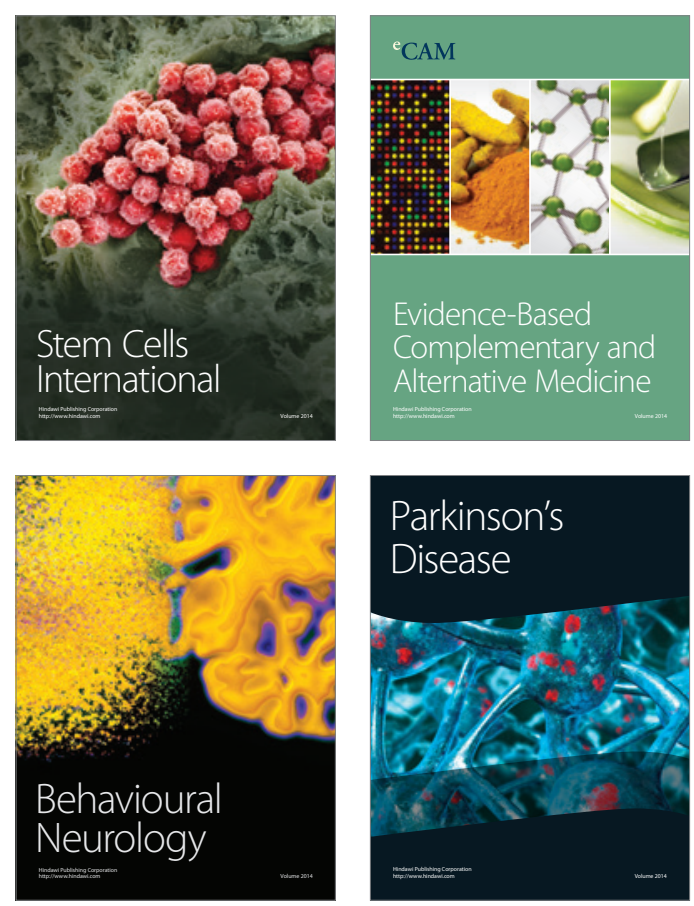

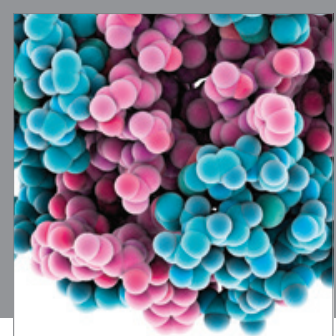

Journal of
Diabetes Research

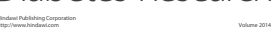

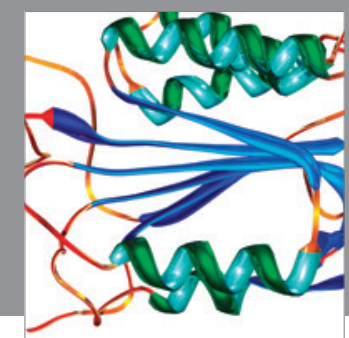

Disease Markers
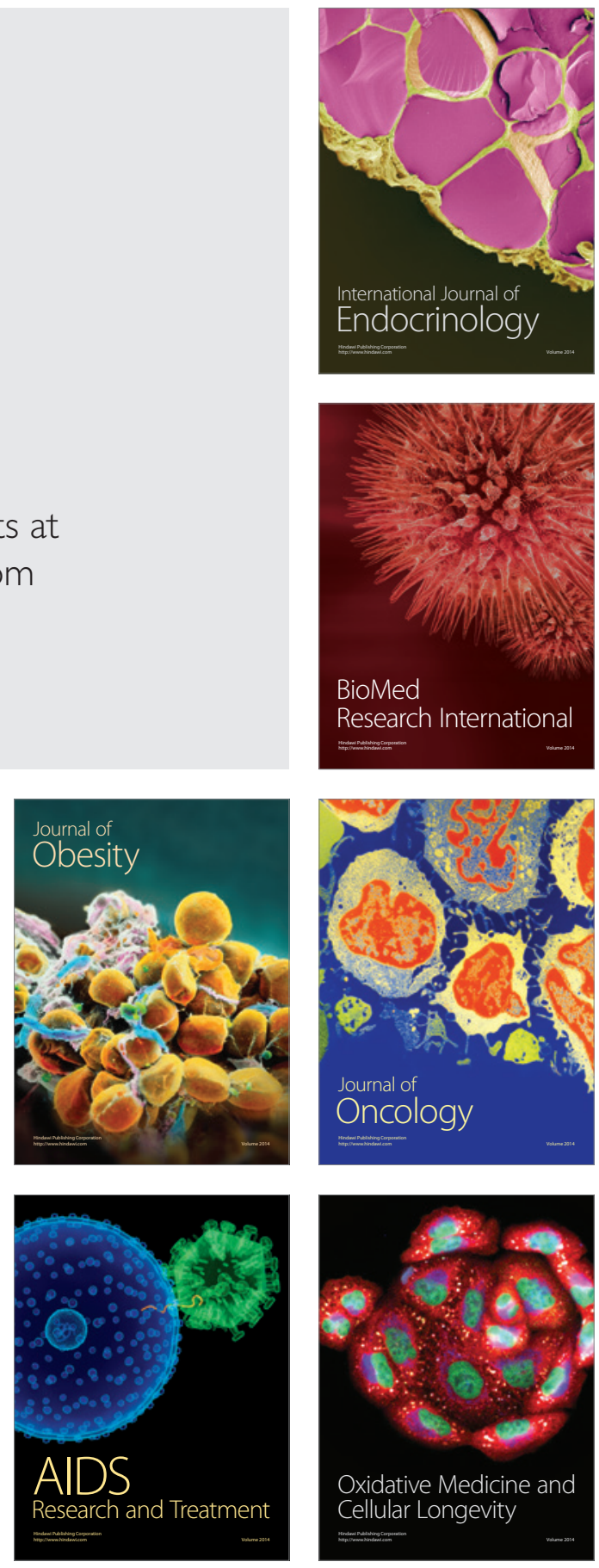